\title{
Molecular techniques applied to investigations of abundance of the ammonia oxidizing bacteria and ammonia oxidizing archaea microorganisms in the environment
}

\author{
Amjed Ginawi ${ }^{1}$, Yunjun Yan ${ }^{2}$ \\ ${ }^{1,2}$ Key Lab of Molecular Biophysics of Ministry of Education, Huazhong University of Science and Technology, China \\ ${ }^{1}$ Faculty of Marine Science and Fisheries, Red Sea University, Sudan
}

\begin{tabular}{l} 
Article Info \\
\hline Article history: \\
Received Dec 20, 2018 \\
Revised Feb 5, 2019 \\
Accepted Feb 15, 2019 \\
\hline
\end{tabular}

\section{Keywords:}

Ammonia oxidizing archaea Ammonia oxidizing bacteria Chemolithoautotrophic bacteria Molecular techniques

\begin{abstract}
This review shows regards of the recently experienced concerning the environments of ammonia oxidizing bacteria (AOB), ammonia oxidizing archaea (AOA) microorganisms, and denitrifying microbes. The advancements of molecular biology techniques have encouraged staggeringly to the fast recent developments in the sector. Various methods for implementing so are discussed. The function of AOB, AOA, and denitrifying microorganism composition was investigated through a high throughput of the 16S rRNA amplicon sequencing protocol. There is potential to observe the specific species appearance of these microorganisms in each environment and get to the evaluated relative abundance of several kinds. There is information indicated which the structure of denitrifying and nitrifying group was monitored field to significant fluctuations and the complexes, together in space and in time. More effort is required to enhance and isolate those microorganisms that common of the progressions and to function them through the compound of molecular techniques, biochemical and physiological. However, the investigation with deoxyribonucleic acid (DNA), antibodies, and the polymerase chain reaction (PCR) was preferred mainly to report the composition of chemolithoautotrophic bacteria, surveys of their characteristics in environmental that needed quantification at the transcriptional level is presently not available.
\end{abstract}

Copyright (C) 2019 Institute of Advanced Engineering and Science. All rights reserved.

\section{Corresponding Author:}

Yunjun Yan,

College of Life Science and Technology,

Huazhong University of Science and Technology,

1037 Luoyu Rd, Hongshan District, Wuhan City, Hubei Province 430074, P. R, China.

Email: yanyunjun@hust.edu.cn

\section{INTRODUCTION}

Ammonia oxidation is the rate-limiting, and first steps of nitrification have been measured extensively because of its environmental importance in the large-scale nitrogen cycle and ecological implications [1]. Ammonia oxidizing and nitrite oxidizing microbes are a two-step process catalyzed. It is just the process of oxidative biological related to reduced and oxidized rivers of nitrogen in environmental [2]. This essential process in the nitrogen cycle of global was considered restricted to ammonia oxidizing bacteria (AOB) [3]. In diverse ecosystems, this processes counteract environmentally, it was applied to reduce nitrogen values in wastewater treatment plants. Various researches influences the essence of methods: autotrophic nitrification in microorganisms [4]; environmental of denitrification and nitrate/nitrite ammonification [5]; factors controlling denitrification [6]; aspects of denitrification in sediment and soil [7]; investigations for functional genes and phylogenetic of denitrification and nitrification [8]; molecular basis and cell biology of denitrification [9]; enzymology of ammonia oxidation [10]; enzymology 
of the nitrogen cycle [11]; aquaculture and nitrifying bacteria [12]; dissimilatory nitrate reductases in microbe [13]; anaerobic ammonia oxidation [14]; inorganic nitrogen metabolism in bacteria [15]; and nitrogen cycling in aquatic ecosystems [16]. The function of microbial communities in freshwater environments was significant in determining the composition [17], presented the diversity of microbial communities and distribution [18].

The functions are an activated related to microorganism groups, e.g., nitrogen fixation; microorganisms are essential processed and in substance, turnover cycling the stream. As gene function target, the ammonia monooxygenase $(a m o A)$ is more functional than the 16S rRNA scheme, for analysis AOA and AOB population pattern [19]. The high concentrations of ammonia in the streams are toxic to fishes and other aquatic living organisms. The reduction of ammonia in the environment is one of the primary functions of (AOA and $\mathrm{AOB}$ ) and attained by nitrification, AOA support nitrification in different habitats. However, the separate study of AOB or AOA functions in ammonia oxidation causing significant attention and attracted many researchers [20].

Ammonia oxidizing archaea and AOB involves the key enzyme the amo $A$ that is constituted of three $a m o A, a m o B$, and the $a m o C$ genes encode subunits [21]. In situ ratio determinations in streams environments, even so, the indicated that nitrification was appeared almost universally, even in the many oligotrophic environments with very lowest concentrations of nitrates under the growth threshold of AOB [22, 23].

The environmental experiences were large variations in chemical conditions and several hydrological. Furthermore, The physiochemical characteristic may affect the population of microbes to processes such as: nitrogen cycling [24], $\mathrm{NH}_{4}{ }^{+}$availability [25], dissolved oxygen (DO) concentrations [26], temperature [27], total nitrogen (TN), total phosphorus (TP) [28], light [29], salinity [30], oxidation-reduction potential (ORP) [31], and sulfide concentrations [32]. Some studies were showed that abundance AOA AOB phylotypes and distinct AOA - AOB groups had been presented in various aquatic environments (freshwater- marine) both in local estuarine gradients and on a wide geographical scale [33, 34]. Moreover, a few is known about whether AOA - AOB microorganisms are essential nitrifies in estuarine and marine environments.

This review is emphasized and highlighted the current achievements in the scope of chemolithoautotrophic bacteria detected through applied approaches of molecular biology, with focus on the natural habitats. There were techniques of engineering such as wastewater treatment plants, oxygen demand, water resources pollutants, and transport of pollutants.

\section{INVESTIGATIONS OF THE COMMUNITIES' COMPOSITION}

The caused by their unique requests that are usually unidentified and decreased levels of growth, it is often not simplified to isolate a pure culture of AOB autotrophic microorganisms. The isolate combined with the typically small amount (few than $0.1 \%$ ), complicated our understandable on the relative abundance and distribution of this microorganism in habitats environmental. However, molecular techniques were appeared to accessible Figure 1.

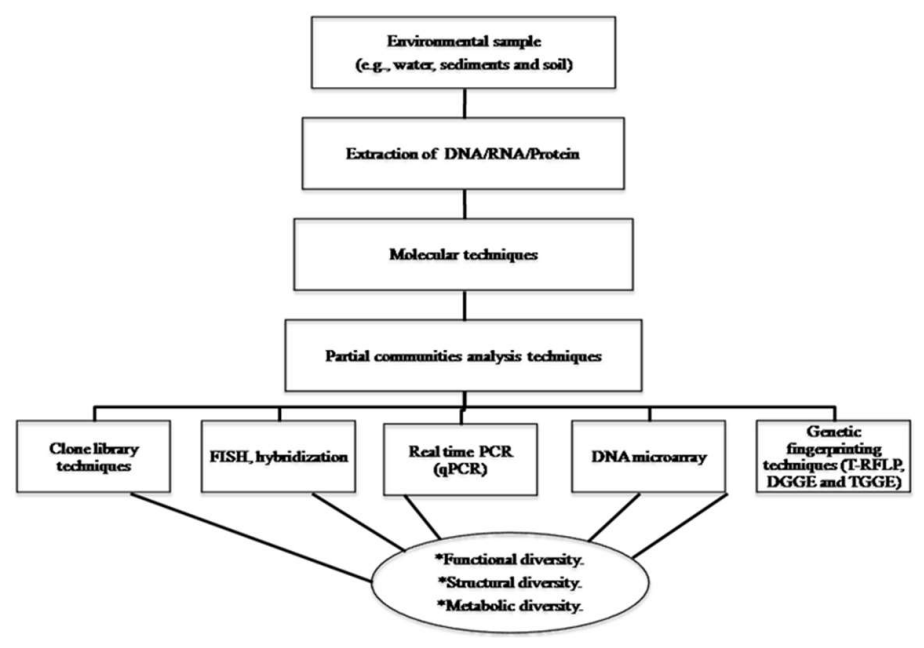

Figure 1. Molecular techniques model to functional diversity of microbes and characterize the structural in the environments

Int. J. of Adv. in Appl. Sci. Vol. 8, No. 1, March 2019: 1 -7 


\subsection{Immunofluorescence technology}

The function of fluorescent polyclonal antibodies (FPA) that identify ammonia monooxygenase (AMO) were functional immunofluorescences to identify ammonia oxidizing microbes [35]. The FPA production depends on the pure cultures accessibility. The diversity of essential serological was shown within the isolates from the various sediment samples [36]. FPA was changed for selective calculating of many Nitrosomonas spp supported the affiliated and suspended microorganism for species-specific counting [37]. For years ago, Nitrosomonas spp were considered to be natural compounds of the microbes [37], and at the minimum the most obvious [38], the AOB in freshwater habitats, whereas Nitrosospira spp. were found to be dominated in sedimentary [39,40]. Through microscopy of immunofluorescence with partial sequence $16 \mathrm{~S}$ ribosomal RNA sequences analysis and DNA hybridization [41, 42]. Furthermore, the novel studies of other places have changed this show.

\subsection{Phylogenetic technology}

The understanding that microorganisms of nitrifying (nitrite and ammonia oxidizers) appeared to the sole of possessing operated for 16S rRNA molecular methods were significantly facilitated analyses of communities $[43,44]$. The understanding of these sequences enables several techniques for analyzing the group structures of nitrifying microorganisms. Many of the experiments have been made for the clade of the AOB within the genus $\beta$-Proteobacteria.

\subsubsection{PCR-based technology}

Up to 1997, 30 oligonucleotides of the 16S rRNA gene sequences are known [45], with understanding specificity for $\mathrm{AOB}$ of the genus $\beta$-Proteobacteria were proposed for PCR or hybridizations with whole cells or DNA and RNA extraction. Almost all the understanding about the AOB diversity groups in natural habitats has been collected to apply oligonucleotides. The primer of the oligonucleotide for Nitrosococcus oceani was described [46, 47], however, have not been extensively used [48].

The PCR with primer sequences of known characteristics was applied to amplification 16S rRNA, $\mathrm{AOB}$, and AOA groups from natural habitat. The use of direct nested PCR facilitates the detection of the family Eubacteriaceae [49] was achieved. In a few situations, modified PCR showed positive significance from samples where direct PCR unsuccessful, that was primarily ascribed to decreased AOB abundance [50]. When surveys of various environmental samples (Soil and water, nutrient-enriched or poor) it showed apparently that Nitrosospira-like AOB is nearly omnipresent [51].

Nitrosospira-like AOB showed to be the dominant AOB and the universally present worldwide. However, Nitrosomonas-like AOB might be identified from several environmental samples. $N$. eutropha/europaea has long been recognized that at lowest $[52,53]$, owing to their possibility to construct microbial extracellular polymers substances [41]. As a strategy of survivability, the exopolymers might be supported recovery after extreme dryness stress in sediments [54], survivability in famine situations [55].

The possibility of identification of members of the N. eutropha / europaea parentage increased with raising nutrient concentrations [56,57]. Occasionally, although sequences of Nitrosomonas-like might not be determined in ecological DNA investigations, enrichment cultures obtained from same habitats detected Nitrosomonas spp $[58,59]$. The considered of obvious that even within various types of sediment (profundal and littoral sediments) distinct communities correlated to either $N$. eutropha or $N$. europaea occurred [60].

Interestingly, during a continuously high number of ecological investigations sequences related to the same AOB clusters were obtained from many various sites (samples of aquatic habitats) with the diversity structure of their 'total' bacterial groups. The statistics were showed the representation of higher abundance within the microbial communities, which just some strains are in culture as described.

In the investigation applying $16 \mathrm{~S}$ rDNA amplicons to the descriptions AOB group in the root zone and the sediment of lakes in the Netherlands, not confirmations were observed which any specific classification/phylogenetic clusters were particular for these periodically low amounts of oxygen conditions [61]. The fertilized of soil huge elevated in nitrification concentration, however not in population size, was assessed by using PCR of competitive depended on $16 \mathrm{~S}$ rRNA and amo $A$ genes. This was proposed phenotypic modification within the AOB group [62]. It could be exciting to find if such changes might be monitored when the aim of the primary proteins mRNAs of ammonia oxidation (AMO, HAO).

Over the past decades after the implementation of terminal restriction fragment length polymorphism (T-RFLP) [63, 64], temperature gradient gel electrophoresis (TGGE), and denaturing gradient gel electrophoresis (DGGE) [65] in environmental microbiology. These approaches are recent generally used in most microbiological laboratories globally as molecular tools to correlate between the diversity of microorganism communities and to observer population dynamics. Recent progress in these approaches has demonstrated their significance in environmental microbiology.

Molecular techniques applied to investigations of abundance of the ammonia oxidizing ... (Amjed Ginawi) 


\subsubsection{Fluorescent in situ hybridization (FISH)}

Various oligonucleotides investigations to determined ammonia oxidizing group of the subclass $\beta$ Proteobacteria have been reported [66, 67], but there is barely a little FISH applications for evaluating of the abundance of nitrifying microorganism in ecosystems. According to the appearance search of the basic local alignment search tool (BLAST), together probes aligned sequences of $16 \mathrm{~S}$ rRNA in ammonia oxidizing group and some unclassified clones. They might be used together because their characteristics are slightly various. The application of determined probes that identify diverse communities of ammonia oxidizing group could be possible only in environments with high ammonia oxidizing group abundances, for example, wastewater treatment plants. Until a little investigation for ammonia oxidizing group of the Proteobacteria has been reported, that could be particularly functional for the counting AOA and AOB groups in aquatic samples.

Microarray technology has considered a high-throughput platform and valuable tool to estimate possible candidate proteins and genes $[68,69]$. DNA microarrays are extensively applied for gene expression $[70,71]$.

\section{CONCLUSION}

Molecular biology approaches have achieved the investigation of unidentified microorganisms and their function in various natural habitats more obtainable. Moreover, we are distanced to knowing the difficulty of microbial in every environmental. Nearly more than one hundred of the diverse genomes per gram occur in soils, and the numbers might be higher in habitats of aquatic likewise. Target DNA (functional genes or 16S rRNA sequences encoding) might be amplified by cloned, sequenced and PCR. The technology such as T-RFLP, TGGE, and DGGE might be facilitated to shown sample sets for the evaluation of regional and seasonal variations. Wherefore most obtained of sequences for functional genes will be novel. The status did not become dramatic in the $16 \mathrm{~S}$ rRNA sequences situation. However, the functions of each environment will increase unique sequence data of the 16S rRNA databanks abundances. Recently molecular technology, like microarrays with various copies of all denitrification and nitrification genes, will potentially help to show of microorganisms for their specific metabolic facilitate in the nitrogen cycle. The knowledge is needed not concerning the bacterial structure, however, the concerning their activities. The excitement about the molecular biology approaches which allow us to investigate microorganisms directly in their environmental, we require extra attempts to develop and characterize molecular methods, those organisms that are still unidentified.

\section{ACKNOWLEDGEMENTS}

This work is financially supported by the National Natural Science Foundation of China (grant No. 31070089, 31170078, and J1103514), the National High Technology Research and Development Program of China (grant Nos. 2013AA065805 and 2014AA093510), the National Natural Science Foundation of Hubei Province (grant No. 2015CFA085), and the Fundamental Research Funds for HUST (grant Nos. 2014NY007, 2017KFYXJJ212, 2017KFXKJC010, 2017KFTSZZ001). Many thanks are indebted to the Analytical and Testing Center of Huazhong University of Science and Technology for the measurements of water quality.

\section{REFERENCES}

[1] Kowalchuk, G.A. and J.R. Stephen, "Ammonia-oxidizing bacteria: a model for molecular microbial ecology," Annu Rev Microbiol, vol. 55, pp. 485-529, 2001.

[2] Martens-Habbena, W., et al., "Ammonia oxidation kinetics determine niche separation of nitrifying Archaea and Bacteria," Nature, vol. 461(7266), pp. 976-9, 2009.

[3] Prosser, J.I. and G.W. Nicol, "Relative contributions of archaea and bacteria to aerobic ammonia oxidation in the environment," Environ Microbiol, vol. 10(11), pp. 2931-41, 2008.

[4] Braker, G. and R. Conrad, "Diversity, structure, and size of N(2)O-producing microbial communities in soils--what matters for their functioning?," Adv Appl Microbiol, vol. 75, pp. 33-70, 2011.

[5] Dong, L.F., et al., "Changes in benthic denitrification, nitrate ammonification, and anammox process rates and nitrate and nitrite reductase gene abundances along an estuarine nutrient gradient (the Colne estuary, United Kingdom)," Appl Environ Microbiol, vol. 75(10), pp. 3171-9, 2009.

[6] Wu, S., et al., "Denitrification and the controlling factors in Yunnan Plateau Lakes (China): Exploring the role of enhanced internal nitrogen cycling by algal blooms," Journal of Environmental Sciences, 2018.

[7] Peter-Contesse, H., "Measuring Denitrification Rates in Soil," Reference Module in Earth Systems and Environmental Sciences, pp. 866-871, 2017.

Int. J. of Adv. in Appl. Sci. Vol. 8, No. 1, March 2019: 1 - 7 
[8] Levy-Booth, D.J., C.E. Prescott, and S.J. Grayston, "Microbial functional genes involved in nitrogen fixation, nitrification and denitrification in forest ecosystems," Soil Biology and Biochemistry, vol. 75, pp. 11-25, 2014.

[9] Alcaman-Arias, M.E., et al., "Diurnal Changes in Active Carbon and Nitrogen Pathways Along the Temperature Gradient in Porcelana Hot Spring Microbial Mat," Front Microbiol, vol. 9, pp. 2353, 2018.

[10] Hooper, A.B., et al., "Enzymology of the oxidation of ammonia to nitrite by bacteria," Antonie Van Leeuwenhoek, vol. 71(1-2), pp. 59-67, 1997.

[11] Ferguson, S.J., "Nitrogen cycle enzymology," Curr Opin Chem Biol, vol. 2(2), pp. 182-93, 1998.

[12] Kuhn, D.D., et al., "Evaluation of nitrifying bacteria product to improve nitrification efficacy in recirculating aquaculture systems," Aquacultural Engineering, vol. 43(2), pp. 78-82, 2010.

[13] Philippot, L. and O. Hojberg, "Dissimilatory nitrate reductases in bacteria," Biochim Biophys Acta, vol. 1446(1-2), pp. 1-23. 1999.

[14] Gao, D., et al., "Anaerobic ammonia oxidizing bacteria: ecological distribution, metabolism, and microbial interactions," Frontiers of Environmental Science \& Engineering, vol. 12(3), 2018.

[15] Norman, J.S., L. Lin, and J.E. Barrett, "Paired carbon and nitrogen metabolism by ammonia-oxidizing bacteria and archaea in temperate forest soils," Ecosphere, vol. 6(10), pp. 176, 2015.

[16] Damashek, J. and C.A. Francis, "Microbial Nitrogen Cycling in Estuaries: From Genes to Ecosystem Processes," Estuaries and Coasts, vol. 41(3), pp. 626-660, 2017.

[17] Lemke, M.J., et al., "Description of freshwater bacterial assemblages from the upper parana river floodpulse system, Brazil," Microb Ecol, vol. 57(1), pp. 94-103, 2009.

[18] Herfort, L., et al., "Variations in spatial and temporal distribution of Archaea in the North Sea in relation to environmental variables," FEMS Microbiol Ecol, vol. 62(3), pp. 242-57, 2007.

[19] Rotthauwe, J.H., K.P. Witzel, and W. Liesack, "The ammonia monooxygenase structural gene amoA as a functional marker: Molecular fine-scale analysis of natural ammonia-oxidizing populations," Applied and Environmental Microbiology, vol. 63(12), pp. 4704-4712, 1997.

[20] Cydzik-Kwiatkowska, A. and M. Zielinska, "Bacterial communities in full-scale wastewater treatment systems," World J Microbiol Biotechnol, vol. 32(4), pp. 66, 2016.

[21] Purkhold, U., et al., "Phylogeny of All Recognized Species of Ammonia Oxidizers Based on Comparative 16S rRNA and amoA Sequence Analysis: Implications for Molecular Diversity Surveys," Applied and Environmental Microbiology, vol. 66(12), pp. 5368-5382, 2000.

[22] Gruber, N. and J.N. Galloway, "An Earth-system perspective of the global nitrogen cycle," Nature, vol. 451(7176), pp. 293-6, 2008.

[23] Horikoshi, K., "Extremophiles Where it all Began," 1st ed, Tokyo: Springer Japan, 2016.

[24] Zeng, J., et al., "Primary Succession of Nitrogen Cycling Microbial Communities Along the Deglaciated Forelands of Tianshan Mountain, China," Front Microbiol, vol. 7, pp. 1353, 2016.

[25] Tong, D. and R. Xu, "Effects of urea and (NH4)2SO4 on nitrification and acidification of Ultisols from Southern China, " Journal of Environmental Sciences, vol. 24(4), pp. 682-689, 2012.

[26] Henriksen, K. and W.M. Kemp, "Nitrification in estuarine and coastal marine sediments: methods, patterns and regulating factors," Nitrogen Cycling in Coastal Marine Environments, ed. T.H. Blackburn and J. Sorensen, New York: John Wiley and Sons, 1986.

[27] Zeng, J., et al., "Temperature responses of ammonia-oxidizing prokaryotes in freshwater sediment microcosms," PLoS One, vol. 9(6), pp. e100653, 2014.

[28] Cao, X., et al., "Bacterioplankton community responses to key environmental variables in plateau freshwater lake ecosystems: A structural equation modeling and change point analysis," Sci Total Environ, vol. 580, pp. 457-467. 2017.

[29] Ward, B.B., "Nitrification and the marine nitrogen cycle," Microbial Ecology, ed. D. Kirchman, New York: WileyLiss. 2000.

[30] Rysgaard, S., et al., "Effects of Salinity on NH 4 + Adsorption Capacity, Nitrification, and Denitrification in Danish Estuarine Sediments," Estuaries, vol. 22(1), pp. 21, 1999.

[31] Li, Z., et al., "Phosphorus release from coastal sediments: Impacts of the oxidation-reduction potential and sulfide," Mar Pollut Bull, vol. 113(1-2), pp. 176-181, 2016.

[32] Joye, S.B. and J.T. Hollibaugh, "Influence of Sulfide Inhibition of Nitrification on Nitrogen Regeneration in Sediments," Science, vol. 270(5236), pp. 623-625, 1995.

[33] Francis, C.A., et al., "Ubiquity and diversity of ammonia-oxidizing archaea in water columns and sediments of the ocean," Proc Natl Acad Sci US A, vol. 102(41), pp. 14683-8, 2005.

[34] Beman, J.M. and C.A. Francis, "Diversity of ammonia-oxidizing archaea and bacteria in the sediments of a hypernutrified subtropical estuary: Bahia del Tobari, Mexico," Appl Environ Microbiol, vol. 72(12), pp. 7767-77, 2006.

[35] Fiencke, C. and E. Bock, "Genera-specific immunofluorescence labeling of ammonia oxidizers with polyclonal antibodies recognizing both subunits of the ammonia monooxygenase," Microb Ecol, vol. 47(4), pp. 374-84, 2004.

[36] Belser, L.W. and E.L. Schmidt, "Serological diversity within a terrestrial ammonia-oxidizing population," Appl. Environ. Microbiol, vol. 36(4), pp. 589-593, 1978.

[37] Bothe, H., et al., "Molecular analysis of ammonia oxidation and denitrification in natural environments," FEMS Microbiol Rev, vol. 24(5), pp. 673-90, 2000.

[38] Pommerening-Röser, A., G. Rath, and H.-P. Koops, "Phylogenetic Diversity within the Genus Nitrosomonas," Systematic and Applied Microbiology, vol. 19(3), pp. 344-351, 1996. 
[39] Mosier, A.C. and C.A. Francis, "Relative abundance and diversity of ammonia-oxidizing archaea and bacteria in the San Francisco Bay estuary," Environ Microbiol, vol. 10(11), pp. 3002-16, 2008.

[40] Pester, M., et al., "amoA-based consensus phylogeny of ammonia-oxidizing archaea and deep sequencing of amoA genes from soils of four different geographic regions," Environ Microbiol, vol. 14(2), pp. 525-39, 2012.

[41] Stehr, G., et al., "Exopolymers: An ecological characteristic of a floc-attached, ammonia-oxidizing bacterium," Microb Ecol, vol. 30(2), pp. 115-26, 1995.

[42] Orjalo, A.V., Jr. and H.E. Johansson, "Stellaris(R) RNA Fluorescence In Situ Hybridization for the Simultaneous Detection of Immature and Mature Long Noncoding RNAs in Adherent Cells," Methods Mol Biol, vol. 1402, pp. 119-134, 2016.

[43] Junier, P., et al., "Community analysis of betaproteobacterial ammonia-oxidizing bacteria using the amoCAB operon," Appl Microbiol Biotechnol, vol. 83(1), pp. 175-88, 2009.

[44] Habteselassie, M.Y., L. Xu, and J.M. Norton, "Ammonia-oxidizer communities in an agricultural soil treated with contrasting nitrogen sources," Front Microbiol, vol. 4, pp. 326, 2013.

[45] Utaker, J.B. and I.F. Nes, "A qualitative evaluation of the published oligonucleotides specific for the 16S rRNA gene sequences of the ammonia-oxidizing bacteria," Syst Appl Microbiol, vol. 21(1), pp. 72-88, 1998.

[46] Ward, B.B. and G.D. O'Mullan, "Worldwide distribution of Nitrosococcus oceani, a marine ammonia-oxidizing gamma-proteobacterium, detected by PCR and sequencing of 16S rRNA and amoA genes," Appl Environ Microbiol, vol. 68(8), pp. 4153-7, 2002.

[47] El Sheikh, A.F., A.T. Poret-Peterson, and M.G. Klotz, "Characterization of two new genes, amoR and amoD, in the amo operon of the marine ammonia oxidizer Nitrosococcus oceani ATCC 19707," Appl Environ Microbiol, vol. 74(1), pp. 312-8, 2008.

[48] Ward, B.B., et al., "Analysis of ammonia-oxidizing bacteria from hypersaline Mono Lake, California, on the basis of 16S rRNA sequences," Appl Environ Microbiol, vol. 66(7), pp. 2873-81, 2000.

[49] Taylor, P.W. and J.R. Winton, "Optimization of Nested Polymerase Chain Reaction Assays for Identification ofAeromonas salmonicida,Yersinia ruckeri, andFlavobacterium psychrophilum," Journal of Aquatic Animal Health, vol. 14(3), pp. 216-224, 2002.

[50] Mahmood, S., T.E. Freitag, and J.I. Prosser, "Comparison of PCR primer-based strategies for characterization of ammonia oxidizer communities in environmental samples," FEMS Microbiol Ecol, vol. 56(3), pp. 482-93, 2006.

[51] Yao, Q. and D.C. Peng, "Nitrite oxidizing bacteria (NOB) dominating in nitrifying community in full-scale biological nutrient removal wastewater treatment plants," AMB Express, vol. 7(1), pp. 25, 2017.

[52] Phillips, C.J., et al., "Phylogenetic differences between particle-associated and planktonic ammonia-oxidizing bacteria of the beta subdivision of the class Proteobacteria in the Northwestern Mediterranean Sea," Appl. Environ. Microbiol., vol. 65(2), pp. 779-786, 1999.

[53] Prosser, J.I., "Autotrophic nitrification in bacteria," Adv Microb Physiol, vol. 30, pp. 125-81, 1989.

[54] Allison, S.M. and J.I. Prosser, "Survival of ammonia oxidising bacteria in air-dried soil," FEMS Microbiology Letters, vol. 79(1), pp. 65-68, 1991.

[55] Xia, X., et al., "Dissolved organic nitrogen transformation in river water: Effects of suspended sediment and organic nitrogen concentration," Journal of Hydrology, vol. 484, pp. 96-104, 2013.

[56] McCaig, A.E., et al., "Nitrogen cycling and community structure of proteobacterial beta-subgroup ammoniaoxidizing bacteria within polluted marine fish farm sediments," Appl Environ Microbiol, vol. 65(1), pp. 213-20, 1999.

[57] Ward, B.B., M.A. Voytek, and K. Witzel, "Phylogenetic Diversity of Natural Populations of Ammonia Oxidizers Investigated by Specific PCR Amplification," Microb Ecol, vol. 33(2), pp. 87-96, 1997.

[58] Hiorns, W.D., et al., "Amplification of 16S ribosomal RNA genes of autotrophic ammonia-oxidizing bacteria demonstrates the ubiquity of nitrosospiras in the environment," Microbiology, vol. 141(Pt 11). pp. 2793-800, 1995.

[59] Ibekwe, A.M., "A. Gonzalez-Rubio, and D.L. Suarez, Impact of treated wastewater for irrigation on soil microbial communities," Sci Total Environ, no. 622-623, pp. 1603-1610, 2018.

[60] Whitby, C.B., et al., "Phylogenetic differentiation of two closely related Nitrosomonas spp. That inhabit different sediment environments in an oligotrophic freshwater lake," Appl Environ Microbiol, vol. 65(11), pp. 4855-62. 1999.

[61] Kowalchuk, G.A., et al., "Community analysis of ammonia-oxidising bacteria, in relation to oxygen availability in soils and root-oxygenated sediments, using PCR, DGGE and oligonucleotide probe hybridisation," FEMS Microbiology Ecology, vol. 27(4), pp. 339-350, 1998.

[62] Ebie, Y., et al., "Comparative analysis of genetic diversity and expression of amoA in wastewater treatment processes," Appl Microbiol Biotechnol, vol. 64(5), pp. 740-4, 2004.

[63] Liu, W.T., et al., "Characterization of microbial diversity by determining terminal restriction fragment length polymorphisms of genes encoding 16S rRNA," Appl Environ Microbiol, vol. 63(11), pp. 4516-22, 1997.

[64] Liesack, W. and P.F. Dunfield, "T-RFLP Analysis," in Environmental Microbiology: Methods and Protocols, J.M. Walker, J.F.T. Spencer, and A.L. Ragout de Spencer, Humana Press: Totowa, NJ, Editors. 2004, pp. 23-37.

[65] Ferris, M.J., G. Muyzer, and D.M. Ward, "Denaturing gradient gel electrophoresis profiles of 16S rRNA-defined populations inhabiting a hot spring microbial mat community," Applied and environmental microbiology, vol. 62(2), pp. 340-346, 1996.

[66] Molina, V., et al., "Ammonia-oxidizing beta-proteobacteria from the oxygen minimum zone off northern Chile," Appl Environ Microbiol, vol. 73(11), pp. 3547-55, 2007.

Int. J. of Adv. in Appl. Sci. Vol. 8, No. 1, March 2019: 1 -7 
[67] Magalhaes, C., et al., "Composition and activity of beta-Proteobacteria ammonia-oxidizing communities associated with intertidal rocky biofilms and sediments of the Douro River estuary, Portugal," J Appl Microbiol, vol. 103(4), pp. 1239-50, 2007.

[68] Csako, G., "Present and future of rapid and/or high-throughput methods for nucleic acid testing," Clin Chim Acta, vol. 363(1-2), pp. 6-31, 2006.

[69] Rensink, W.A. and C.R. Buell, "Microarray expression profiling resources for plant genomics," Trends Plant Sci, vol. 10(12), pp. 603-9, 2005

[70] Makretsov, N., et al., "A fluorescence in situ hybridization study of ETV6-NTRK3 fusion gene in secretory breast carcinoma," Genes Chromosomes Cancer, vol. 40(2), pp. 152-7, 2004.

[71] Brown, L.A., et al., "Amplification of EMSY, a novel oncogene on 11q13, in high grade ovarian surface epithelial carcinomas," Gynecol Oncol, vol. 100(2), pp. 264-70, 2006. 